\title{
Comparison of Sublingual Captopril and Sublingual Nifedipine in Hypertensive Emergencies
}

\author{
Berrin CEYHAN, Yaşar KARAASLAN, Oguz CAYMAZ, Ali OTO** \\ Erdem ORAM, Aysel ORAM and Şevket UGURLU \\ Department of Cardiology. Hacettepe University. Faculty of Medicine. Ankara. Turkey \\ Accepted October 9.1989
}

\begin{abstract}
Hypertensive crises require immediate therapy, usually by parenteral drug administration. Sublingual nifedipine has been shown to be highly effective. However, the blood pressure fall following nifedipine is frequently associated with side-effects. The use of sublingual captopril has recently been indicated in hypertensive crisis, assuming that by this route, there would be a faster absorption and thus a more rapid effect on blood pressure than with the oral route. To verify this hypothesis, we have compared the hypotensive effects of sublingual nifedipine and sublingual captopril in 52 patients with hypertensive emergencies: 25 -mg captopril and $10-\mathrm{mg}$ nifedipine were administered sublingually to 28 and 24 patients, respectively. Blood pressures and heart rates were continuously measured up to $240 \mathrm{~min}$ postdose. A significant $(P<0.001)$ hypotensive effect of both sublingual captopril and nifedipine therapy occured at $5 \mathrm{~min}$ and persisted for $240 \mathrm{~min}$. Heart rates increased with nifedipine, but decreased with captopril. We observed no sideeffects in the captopril group, but flushing, tachycardia and headache were observed in 6 patients in the nifedipine group. We conclude that sublingual captopril is effective in patients with hypertensive emergencies and that captopril may be an excellent alternative to sublingual nifedipine in the urgent treatment of hypertensive crisis.
\end{abstract}

It is well-known that sublingual nifedipine is highly effective in the treatment of hypertensive crisis (1-3). However, the decrease of blood pressure following nifedipine is frequently associated with a reflex tachycardia and flushing. These side-effects, particularly tachycardia. may be hazardous in hypertensive crisis associated with angina pectoris.

Several oral antihypertensive agents have recently been studied in hypertensive crisis. Oral captopril therapy has been found to be effective in hypertensive situations, but usually needs $1-2$ hours to achieve a maximum effect (4-6).

In this study, we administered sublingual captopril to seek a potential alternative drug to sublingual nifedipine in patients with hypertensive emergencies.

\footnotetext{
* To whom correspondence should be addressed.
}

\section{Materials and Methods}

Fifty-two patients (12 males and 40 females) who participated in this study were subdivided into the two groups: 24 patients (18 females and 6 males, aged $58 \pm 3$ years (mean \pm S.E.M.), and weighing $66 \pm 3 \mathrm{~kg}$ ) in the nifedipine group and 28 patients (22 femeles and 6 males, aged $54 \pm 2$ years, and weighing $54 \pm 2 \mathrm{~kg}$ ) in the captopril group. All patients had blood pressure higher than 180/ $120 \mathrm{mmHg}$ in two different measurements, five minutes apart. All of the patients were admitted to the emergency department with symptoms of acute hypertensive crises, and they agreed to take part in the present study. Each patient was told to chew the capsule of nifedipine $(10 \mathrm{mg})$ or place the tablet of captopril (25 mg) under their tongue and to swallow the saliva. Blood pressure and heart 
rate were serially measured in the sitting position before and at $5,10,15,30,45,60,90$. 120 and 240 min after sublingual dosing of nifedipine or captopril. The patients sat on a chair in a quiet room and had no other treatment during this period. The patients were randomized either to nifedipine or to captopril therapy.

Fifteen of 28 patients in the captopril group had been treated previously with various antihypertensive agents: 3 patients were on prazosin and 2 patients were on acebutolol treatment regularly, but ten patients had discontinued their previous therapy on admission. Sixteen of 24 patients in the nifedipine group had been treated previously with the following drugs: 6 patients on nifedipine. 2 on prazosin, 1 on indapamide and 1 on nitrendipine therapy and 6 patients had withdrawn from their previous therapy on admission.

Statistical difference between the baseline or predose and postdose hemodynamics in the two treatment groups were evaluated by a paired $t$-test. Statistical difference in hemodynamics between the two treatment groups was evaluated by an unpaired $t$-test. A Pvalue of 0.05 was considered statistically significant. The data are presented as meant S.E.M. throughout the text.

\section{Results}

There was no significant difference be- tween the demographic data of the two treatment groups.

The mean ( \pm S.E.M.) pre- and postdose blood pressures and heart rates in the two treatment groups are summarized in Table 1 . The mean blood pressure and heart rate data before and up to $240 \mathrm{~min}$ after both sublingual dosings are shown in Figs. 1 and 2, respectively. A significant $(P<0.001)$ blood pressure reduction occurred at $5 \mathrm{~min}$ postdose and persisted throughout the entire observation period after the sublingual administration of both nifedipine and captopril (Table 1), as compared with the respective predose or baseline blood pressure values. Nifedipine increased heart rates significantly $(P<0.05$ to $P<0.01$ ) at 5 to 240 min postdose, whereas captopril decreased heart rates significantly $(P<0.001$ ) at 15 to $240 \mathrm{~min}$ postdose (Table 1).

When the hypotensive effects of these two drugs were compared, sublingual nifedipine had a more $(P<0.05$ to $P<0.001)$ hypotensive effect than sublingual captopril at 10 to $240 \mathrm{~min}$ postdose (Fig. 1). The mean values for heart rate compared between nifedipine and captopril at 5 to $240 \mathrm{~min}$ did not reach statistically significant differences (Fig. 2), although nifedipine increased the postdose heart rate from the baseline.

No one complained of any side-effects in the captopril group, but 6 patients (25\%) in the nifedipine group complained of flushing,

Table 1. The effects of sublingual captopril and sublingual nifedipine on blood pressure (BP) and heart rate $(\mathrm{HR})$ in each group

\begin{tabular}{rcccc}
\hline Time (min) & \multicolumn{2}{c}{ Captopril } & \multicolumn{2}{c}{ Nifedipine } \\
& BP & HR & BP & HR \\
0 & $204 \pm 4 / 123 \pm 2$ & $86 \pm 2$ & $201 \pm 6 / 126 \pm 2$ & $76 \pm 3--$ \\
5 & $193 \pm 5^{* * *} / 117 \pm 3^{*}$ & $84 \pm 2$ & $183 \pm 6^{*} / 113 \pm 2^{*}$ & $79 \pm 3^{* * *}$ \\
10 & $182 \pm 4^{* *} / 115 \pm 3^{*}$ & $84 \pm 2$ & $174 \pm 5^{*} / 106 \pm 3^{*}$ & $81 \pm 3^{* * *}$ \\
15 & $175 \pm 4^{*} / 111 \pm 3^{*}$ & $81 \pm 2^{*}$ & $156 \pm 4^{*} / 98 \pm 2^{*}$ & $83 \pm 3^{* *}$ \\
30 & $166 \pm 4^{*} / 106 \pm 3^{*}$ & $79 \pm 2^{*}$ & $148 \pm 3^{*} / 93 \pm 2^{*}$ & $84 \pm 3^{* *}$ \\
45 & $164 \pm 4^{*} / 104 \pm 3^{*}$ & $80 \pm 2^{*}$ & $151 \pm 3^{*} / 90 \pm 2^{*}$ & $84 \pm 3^{* *}$ \\
60 & $159 \pm 4^{*} / 101 \pm 2^{*}$ & $80 \pm 2^{*}$ & $145 \pm 4^{*} / 90 \pm 2^{*}$ & $84 \pm 3^{* *}$ \\
90 & $156 \pm 4^{*} / 102 \pm 2^{*}$ & $78 \pm 2^{*}$ & $145 \pm 4^{*} / 90 \pm 2^{*}$ & $85 \pm 3^{* *}$ \\
120 & $158 \pm 4^{*} / 102 \pm 3^{*}$ & $78 \pm 2^{*}$ & $144 \pm 4^{*} / 89 \pm 2^{*}$ & $85 \pm 3^{* *}$ \\
240 & $154 \pm 4^{*} / 98 \pm 2^{*}$ & $79 \pm 2^{*}$ & $143 \pm 3^{*} / 88 \pm 2^{*}$ & $85 \pm 3^{* *}$ \\
\hline
\end{tabular}

The data are given as meantS.E.M. ${ }^{*} \mathrm{P}<0.001 .{ }^{*} \mathrm{P}<0.01 .{ }^{* *} \mathrm{P}<0.05$ compared with the respective baseline or predose values. 


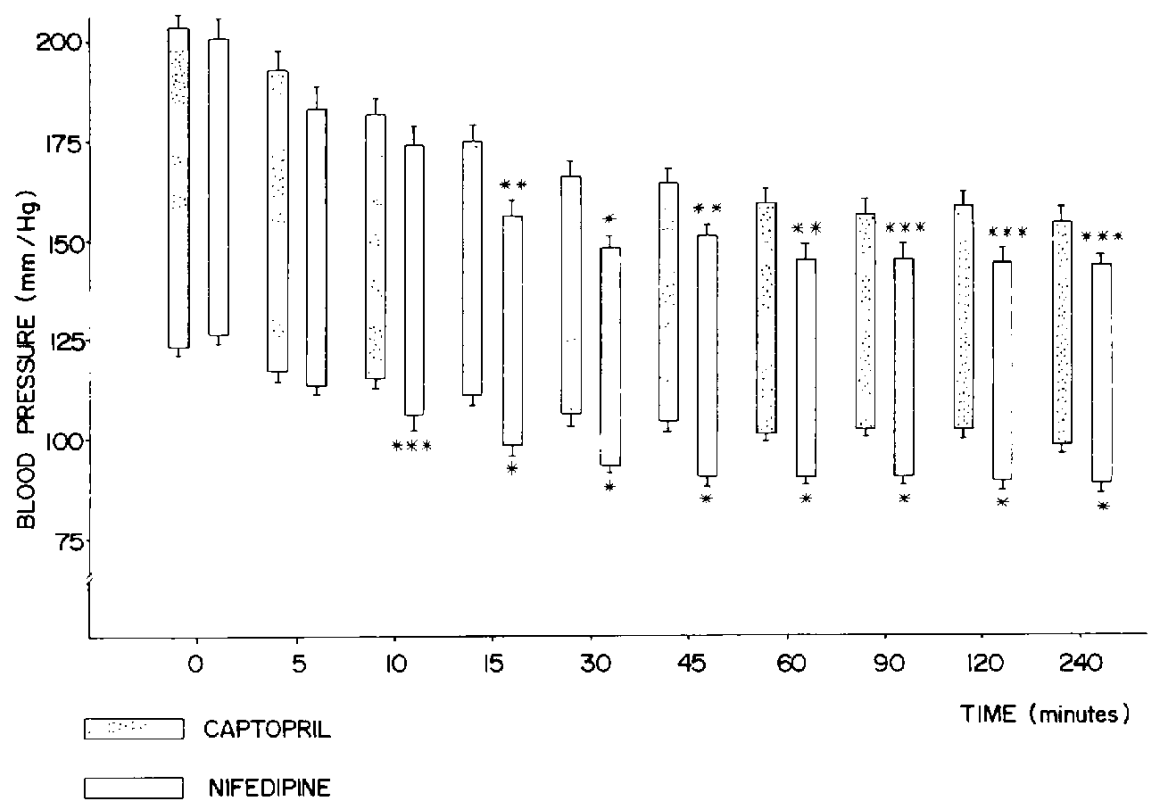

Fig. 1. The effects of sublingual captopril and nifedipine on blood pressure. ${ }^{*} P<0.001,{ }^{* *} P<0.01$ and $* * * P<0.05$ compared with sublingual captopril therapy.

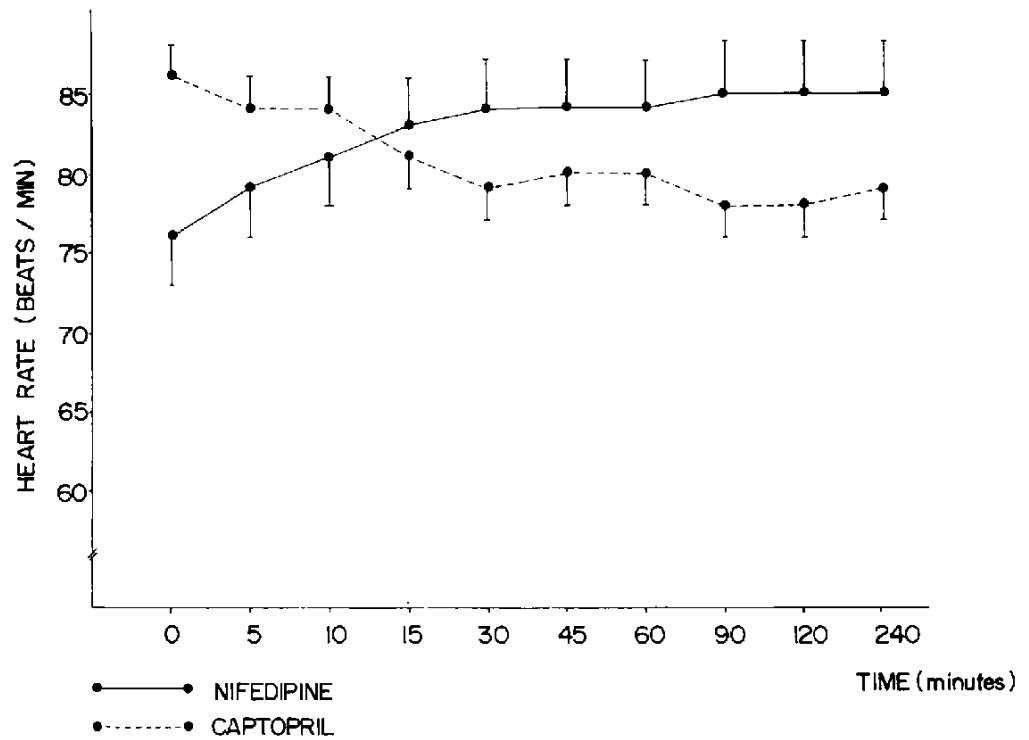

Fig. 2. The effects of sublingual captopril and nifedipine on heart rate. There were no statistically significant differences in postdose heart rates between the two sublingual treatment groups.

tachycardia and/or headache.

\section{Discussion}

Our results support the hypothesis that sublingual captopril is effective in the treatment of hypertensive emergencies. The comparison of sublingual captopril with sublingual nifedipine showed that sublingual 
nifedipine had a more powerful antihypertensive effect than sublingual captopril. Sublingual nifedipine caused tachycardia. flushing and headache, but sublingual captopril therapy was free of these side-effects.

Treatment of hypertensive emergencies requires the use of a drug that possesses a rapid onset of action. Parenteral use of the agents such as nitroprusside, diazoxide, trimethaphan, hydralazine and methyldopa has been a generally accepted strategy for the treatment of hypertensive emergency (7). Nifedipine has been found to be efficient in the treatment of hypertensive emergency with advantage of being a non-parenteral agent (1-3). Houston et al. (1), who reviewed 21 studies (totally 455 patients), concluded that nifedipine administered orally. sublingually. buccaly or rectally in hypertensive urgencies produces a prompt, consistent, dose-related and safe reduction in arterial pressure with few side-effects.

Serious and sometimes fatal complications of treatment in hypertensive crises have been reported for nearly all drugs, such as sodium nitroprusside, diaxozide, methyldopa and hydralazine (8). Sublingual nifedipine has been a preferred agent for hypertensive crisis with increasing cerebral blood flow (2)

Captopril is effective in many forms of hypertension and especially indicated for patients with a high-renin hypertension or hypertension complicated by diabetes mellitus or congestive heart failure $(6,9,10)$ as well as with hypertensive emergency. For example. Tschollar and Belz (11) reported the effects of sublingual captopril in hypertensive crises. The other studies confirmed the efficacy of sublingual captopril and noted that the hypotensive effect persisted for several hours with a duration similar to an oral dose $(12,13)$

Hauger-Klevene (14) compared the hypotensive effect of sublingual captopril with that of sublingual nifedipine. The results showed the similar hypotensive effect, but the decrease in blood pressure levels induced by sublingual nifedipine occurred earlier than by sublingual captopril. Opie and Jennings (15) preferred sublingual nifedipine to sublingual captopril because of contraindication to captopril in patients with renal artery stenosis (16). Pujadas et al. (17) also compared the hypotensive effect of sublingual captopril with that of sublingual nifedipine in 50 patients. They could not find any difference between these two drugs during 6 hours of observation. Brunner et al. (18) found that intravenous enalapril and nifedipine were equally effective in acutely lowering blood pressure.

In our study both of the drugs sublingually administered cecreased blood pressures similarly $(P<0.001)$ and these effects persisted during $240 \mathrm{~min}$. However, the hypotensive effect of sublingual nifedipine was somewhat more powerful than that of sublingual captopril, but we observed some sideeffects only in the nifedipine group.

We concluded that both nifedipine and captopril sublingually administered are effective and safe alternative drugs for managing hypertensive emergencies. They will be used as a first-line drug in the treatment of this condition, since they are easy to administer, they have a rapid onset of action, and they do not induce an exaggerated fall in blood pressure. Captopril with no apparent side-effect(s) seems to be a potential alternative drug for the treatment of hypertensive emergencies. Thus, sublingual captopril appears to be more promising, while further studies are obviously necessary to compare it to other antihypertensive regimens used for the treatment of hypertensive emergency.

\section{References}

1 Houston. M.C.: Treatment of hypertensive urgencies and emergencies with nifedipine. Am. Heart J. 111, 963-969 (1986)

2 Bertel, O., Conen, D., Radü, E.W., Müller, J., Lang, C. and Dubach, U.C.: Nifedipine in hypertensive emergencies. Br. Med. J. 286, $19-$ 21 (1983)

3 Huysmans, E.Th.M., Sluiter, H.E., Thien, Th.A. and Koene, R.A.P.: Acute treatment of hypertensive crisis with nifedipine. Br. J. Clin. Pharmacol. 16, 725-727 (1983)

4 Frohlih, E.D., Cooper, R.A. and Lewis, E.J.: Review of the overall experience of captopril in hypertension. Arch. Intern. Med. 144, 14411444 (1984)

5 Kayanakis, J.G. and Baulac, L.: Comparative study of once daily administration of captopril $50 \mathrm{mg}$. hydrochlorothiazide $25 \mathrm{mg}$ and their 
combination in mild to moderate hypertension. Br. J. Clin. Pharmacol. 23, 89S-92S (1987)

6 Gavras, I. and Gavras, $H_{\text {.: }}$ Clinical utility of angiotensin converting enzyme inhibitors in hypertension. Am. J. Med. 81 (Supp. 4C) , 2831 (1986)

7 Koch-Weser, J.: Hypertensive emergencies. N. Engl. J. Med. 290, 211-214 (1974)

8 Graham, D.I.; Ischaemic brain damage of cerebral perfusion failure type after treatment of severe hypertension. Br. Med. J. 2, 739 (1975)

9 Levine, T.B., Olivari, M.T. and Cohn, J.N.: Angiotensin converting enzyme inhibitors in congestive heart failure. Overview in comparison of captopril and enalapril. Am. J. Med. 81, (Supp. 4C), 36-39 (1986)

10 Pfeffer, J.M., Pfeffer, M.A. and Braunwald, E.; Hemodynamic benefits and prolonged survival with long-term captopril therapy in rats with myocardial infarction and heart failure. Circulation 75 (Supp. 1), 1-149-1-155 (1987)

11 Tschollar, W. and Belz, G.G.: Sublingual captopril in hypertensive crisis. Lancet 2, 34-35 (1985)

12 Dessi Fulgheri, P., Bandiera, F., Rubattu, S., Cocco, F., Madeddu, P., Oppes, M., Tonolo, G.C., Glorioso, N. and Rappelli, A.: Comparison of sublingual and oral captopril in hypertension. Clin. Exp. Hypertens. A.9. 593-597 (1987)

13 Hauger-Klevene, J.H.: Captopril in hypertensive crisis. Lancet 2, 732-734 (1985)

14 Hauger-Klevene, J.H.: Comparison of sublingual captopril and nifedipine. Lancet 2, 219 (1986)

15 Opie, L.H. and Jennings, A.: Subiingual captopril versus nifedipine in hypertensive crisis. Lancet 2, 555 (1985)

16 Hricik, D.E., Browning, P.J., Kopelman, R., Goorno, W.E., Madias, N.E. and Dzau, V.J.: Captopril-induced functional renal insufficiency in patients with bilateral renal artery stenosis or renal artery stenosis in a solitary kidney. $N$. Engl. J. Med. 308, 373-376 (1986)

17 Pujadas, R., Jane, J., Fornos, C., Gago, M.J. and Concepcion, N.: Comparison of sublingual captopril and nifedipine in hypertensive crises. Arch. Intern. Med. 147, 175-176 (1987)

18 Brunner, H.R., Nussberger, J., Bidiville, J., Waeber, G., Porchet, M. and Waeber, B.: Acute antihypertensive effect of angiotensin converting enzyme inhibition and calcium entry blockade. J. Cardiovasc. Pharmacol. 10 (Supp. 10). $587-589(1987)$ 